\title{
PENGARUH SISTEM PENYAMBUNGAN KOPI ARABIKA DENGAN ROBUSTA TERHADAP PERTUMBUHAN DAN PRODUKSI KOPI ARABIKA
}

\section{EFFECT OF ARABICA AND ROBUSTA GRAFTING SYSTEM ON GROWTH AND YIELD OF ARABICA COFFEE}

\author{
Girindra Yoga Aditya ${ }^{1}$, Rusdi Evizal ${ }^{1 *}$, Hidayat Pujisiswanto ${ }^{2}$, Setyo Dwi Utomo $^{2}$ \\ ${ }^{1}$ Jurusan Agroteknologi, Fakultas Pertanian, Universitas Lampung, Bandar Lampung, Indonesia \\ ${ }^{2}$ Jurusan Agronomi, Fakultas Pertanian, Universitas Lampung, Bandar Lampung, Indonesia \\ *Email: rusdi.evizal@fp.unila.ac.id \\ * Corresponding Author, Diterima: 12 Feb. 2021, Direvisi: 6 Apr. 2021, Disetujui: 7 Apr. 2021
}

\section{ABSTRACT}

The performance of Robusta coffee can be improved through intraspecific grafting (Robusta / Robusta) to produce higher yield or through interspecific grafting (Arabica / Robusta) to produce Arabica coffee which has higher quality. The purpose of this research is to study the growth and yield of grafted coffee compared to non-grafted coffeeandto study the growth and yieldof interspesific grafted Arabica compared to non-grafted Arabica. This research was conducted in a farmer's coffee field, in Desa Harapan Jaya, Way Ratai, Pesawaran District. The design used in this research was Randomized Block Design (RBD) with six treatments ofgrafting systemsand four replications. The treatmentswere: P1=non-grafting of Robusta, $P 2=$ non-grafting of Arabica, $P 3=$ grafting of Robusta/Robusta by tak-ent system, P4= grafting of Arabica/Robusta rootstock + branches, P5= grafting scion of the orthotropic Arabica/Robusta, P6 = grafting scion of plagiotropic Arabica/Robusta. The Robusta of Mekarsari clone and Arabica Kartika variety were used in this research. Data were analyzed using the Least Significant Difference Test for mean separation. The resuts showed that each treatment affects significantly to the number of primerybranches, the number of plagiotropicbranches (B0, B1, and B2), the flower bunch per branch, the pistil per branch, the number of green seeds per branch, the number of red seeds per branch, the weight of fresh seeds per branch. The weight of dried seeds per branch, the number of harvested seeds per branch and the yieldper tree. Based on the results, it can be concluded that: (1) the growth and yield of grafted coffee is higher than those of nongrafted coffee; (2) among the system of Arabica coffeeinterspesific Grafting, the treatment of grafting scion of plagiotropic Arabica on rootstock of Robustashowed the same results for growth variablesbut produce higher yield compared to others Arabica grafting system.

Keywords: Arabica, grafting,interspesific, Robusta, plagiotropic, orthotropic, yield

\begin{abstract}
ABSTRAK
Penyambungan (grafting) merupakan salah satu upaya untuk memperbaiki sifat tanaman menggunakan bahan klonal baik pada fase pembibitan, pemeliharaan maupun rehabilitasi. Keragaan sifat kopi Robusta dapat diperbaiki melalui penyambungan intraspesifik (Robusta/Robusta) untuk menghasilkan produktivitas yang lebih tinggi atau melalui penyambungan interspesifik (Arabika/Robusta) untuk menghasilkan kopi Arabika. Tujuan penelitian ini adalah untuk (1) mengetahui pertumbuhan dan produksi kopi grafting dibandingkan dengan kopi non-grafting
\end{abstract}


dan (2) mengetahui pertumbuhan dan produksi kopi grafting Arabika interspesifik dibandingkan dengan Arabika non-grafting. Penelitian ini dilaksanakan di Desa Harapan Jaya, Kecamatan Way Ratai, Kabupaten Pesawaran, Lampung. Rancangan yang digunakan adalah Rancangan Acak Kelompok (RAK) dengan perlakuan enam sistem penyambungan dengan empat ulangan. Perlakuan pada penelitian ini yaitu: $\mathrm{P} 1=$ Robusta non-grafting, $\mathrm{P} 2=\mathrm{Arabika}$ non-grafting, P3 = grafting Robusta/Robusta metode tak-ent, P4= grafting Arabika/Robusta + cabang, P5= grafting Arabika orthrotrop/Robusta, $\mathrm{P} 6=$ grafting Arabika plagiotrop/Robusta. Penelitian ini menggunakan jenis kopi Robusta klon lokal Mekarsari, sedangkan untuk jenis kopi Arabika menggunakan varietas Kartika. Data dianalisis menggunakan uji lanjut yaitu Uji Beda Nyata Terkecil (BNT). Hasil penelitian menunjukkan bahwa masing masing perlakuan berpengaruh nyata terhadap variabel jumlah cabang primer, jumlah cabang plagiotrop (B0, B1, dan B2), jumlah dompol bunga per cabang, jumlah dompol putik per cabang, jumlah dompol buah hijau per cabang, jumlah dompol buah merah per cabang, bobot buah segar per cabang, bobot biji kering per cabang, jumlah biji panen per cabang, dan produksi per pohon. Berdasarkan hasil penelitian ini disimpulkan bahwa: (1) pertumbuhan dan produksi tanaman kopi grafting lebih tinggi daripada tanaman non-grafting, (2) dari berbagai sistem penyambungan kopi Arabika grafting interspesifik, perlakuanArabika plagiotrop/Robusta menghasilkan pertumbuhan yang sama tetapi memberikan produksi biji lebih tinggi dibandingkan dengan perlakuan Arabika lainnya.

Kata kunci : Arabika, grafting, interspesifik, Robusta, plagiotrop, orthrotrop

\section{PENDAHULUAN}

Indonesia merupakan salah satu negara produsen kopi yang penting. Menurut Pusat Data dan Informasi Pertanian (2016), areal kopi di Indonesia mencapai 1.230.495 ha. Produksi kopi Indonesia mencapai 572.460 ton menempati urutan terbesar keempat setelah Brasil, Vietnam, dan Colombia. Produksi kopi Brasil mencapai 3.212.400 ton, Vietnam 1.758.000 ton, yang disusul oleh Kolombia dengan 676.284 ton.

Propinsi Lampung merupakan sentra produksi kopi Robusta, dengan luas areal tahun 2018 mencapai 156.878 ha dan produksi 110.570 ton. Di Lampung, luas areal kopi Arabika tercatat hanya 41 ha dengan produksi 27 ton, sedangkan di Jambi mencapai 1.857 ha dengan produksi 596 ton, dan di Bengkulu mencapai luas 1.536 ha dengan produksi 789 ton (Direktorat Jenderal Perkebunan, 2019).

Menurut Rahardjo (2012), kopi merupakan komoditas yang memiliki nilai ekonomis tinggi dibandingkan komoditas perkebunan lain, tidak hanya sebagai sumber devisa negara, kopi juga dapat meningkatkan kesejahteraan para petani apabila petani menerapkan sistem budidaya yang baik dan benar sehingga diperoleh produktivitas dan kualitas yang tinggi.

Produktivitas kebun kopi dapat ditingkatkan dengan cara intensifikasi, antara lain melalui pemupukan, pemangkasan, dan klonisasi melalui penyambungan. Khususnya kopi Robusta dimana memiliki sifat penyerbukan silang maka seharusnya dibudidayakan pohon klonal yang unggul. Grafting pemeliharaan atau rejuvenasi kopi Robusta sudah dianjurkan sejak zaman kolonial yang dikenal sebagai penyambungan sistem tak-ent yaitu menggunakan "tak-entrijs" dari cabang kipas ataupun dari cabang pecut (Coolhaas, 1953).

Dengan semakin terbatasnya lahan untuk perluasan perkebunan kopi, upaya peningkatan produksi kopi melalui intensifikasi dan rehabilitasi sangat penting. Klonisasi pada tanaman dewasa merupakan 
upaya perbaikan genetik tanaman dengan cara penyambungan (grafting) rejuvenasi intraspesifik untuk meningkatkan produksi kopi. Sistem ini mendorong seleksi dan pemanfaatan beragam klon lokal spesifik lokasi (Evizal dan Prasmatiwi, 2019) dan toleran terhadap variabilitas cuaca (Evizal et al., 2020).

Selain itu, penyambungan dapat digunakan petani kopi khususnya petani kopi Robusta apabila ingin memproduksi kopi Arabika. Dengan cara ini, petani tidak harus melakukan konversi pertanaman kopi Robusta menjadi kopi Arabika melainkan dapat melakukan penyambungan interspesifik Arabika/ Robusta. Dengan cara ini, petani melakukan diversifikasi produk yaitu menghasilkan dua produk sekaligus yaitu kopi Robusta dan kopi Arabika yang memiliki cita rasa dan harga yang lebih tinggi (Evizal dan Prasmatiwi, 2020).

Penyambungan kopi secara interspesifik memanfaatkan keunggulan batang bawah dari jenis kopi yang berbeda misalnya keunggulan pertumbuhan, ketahanan terhadap cekaman lingkungan dan ketahanan terhadap penyakit akar terutama nematoda puru akar. Contohnya adalah penyambungan Arabika/Robusta, Arabika/Liberika dan Robusta/Liberika. Keberhasilan penyambungan, pertumbuhan dan produksi sistem ini sudah dilaporkan antara lain oleh Bertrand and Etienne (2011), Evizal (2013) dan Evizal et al. (2018).

Penyambungan menggunakan batang bawah kopi Liberika yang tahan nematoda menekan serangan nematoda, meningkatkan pertumbuhan dan produksi serta mengurangi mortalitas pohon (Myers et al., 2020) dan cocok untuk untuk diterapkan pada penanaman ulang kopi pada lahan terinfeksi nematoda (Pham et $a l .$, 2020). Peningkatan fotosintesis kopi sambungan akan mendorong peningkatan pertumbuhan dan produksi kopi sambungan (Novaes et al., 2011).

Keberhasilan penyambungan (grafting) interspesifik Arabika/Robusta kopi dewasa dalam meningkatkan produksi masih belum banyak dilaporkan. Tujuan penelitian ini adalah untuk (1) mempelajari pertumbuhan dan produksi kopi grafting dibandingkan dengan kopi non-grafting dan (2) untuk mempelajari pertumbuhan dan produksi kopi grafting Arabika interspesifik dibandingkan dengan Arabika non-grafting.

\section{BAHAN DAN METODE}

Penelitian ini dilaksanakan di Desa Harapan Jaya, Kecamatan Way Ratai, Kabupaten Pesawaran. Kecamatan Way Ratai merupakan dataran tinggi perbukitan dan pegunungan dengan ketinggian sekitar $1000 \mathrm{~m}$ dari permukaan laut dengan curah hujan berkisar $3.500 \mathrm{~mm} /$ tahun. Penelitian ini dilaksanakan selama 6 bulan, dari bulan Oktober 2019 sampai April 2020.

Penelitian ini dilakukan pada kebun kopi Robusta dan Arabika milik petani yang sudah melakukan penyambungan, dengan menggunakan teknik grafting top cleft graft yaitu pada bagian sayatan batang bawah dilakukan pada bagian tengah, kemudian untuk batang atas sayatan diberikan di dua belah sisi yang membentuk hurufv (Suwandi, 2015). Batang bawah yang digunakan adalah kopi Robusta berumur 20 tahun. Sebagai batang atas digunakan entres Robusta dan entres Arabika berumur 3 bulan. Pengamatan mulai dilakukan pada 34 bulan setelah grafting. 
Percobaan ini menggunakan Rancangan Acak Kelompok (RAK) dengan enam perlakuan yang berupa sistem penyambungan dengan 4 kali ulangan, sehingga terdapat 24 satuan percobaan yang masing-masing terdiri dari 5 pohon. Perlakuan pada penelitian ini yaitu: $\mathrm{P} 1=$ Robusta non-grafting (R); P2= Arabika nongrafting (A); P3= grafting Robusta Mekarsari/Robusta Kedondong secara tak-ent yaitu menggunakan entres plagiotrop (RR); P4= Penyambungan batang atas Arabika dengan batang bawah Robusta + cabang $(\mathrm{ARC}) ; \mathrm{P} 5=$ Penyambungan batang atas Arabika Orthrotrop dengan batang bawah Robusta (AOR); P6= Penyambungan batang atas Arabika Plagiotrop dengan batang bawah Robusta (APR). Kopi Robusta untuk batang bawah menggunakan varietas Kedondong, batang atas menggunakan klon Mekarsari, sedangkan untuk jenis kopi Arabika menggunakan varietas Kartika.

Pengamatan dimulai setelah dilakukan penyambungan berumur 34 BSG (Bulan Setelah Grafting) atau mulai diamati pada bulan Oktober 2019 sampai April 2020 setiap satu bulan sekali. Variabel pertumbuhan yang diamati terdiri dari panjang cabang primer, jumlah cabang primer PI dan PII ( PI = Pengamatan jumlah cabang primer bulan Oktober 2019, PII = Pengamatan jumlah cabang primer bulan April 2020), jumlah cabang plagiotrop B0 (cabang yang belum berbuah), B1 (cabang yang sedang berbuah pertama kali), B2 (cabang yang sedang berbuah kedua kali), diameter cabang primer, diamater batang bawah, panjang cabangujung produktif, danketerjadiankarat daun.

Variabel produksi yang diamati terdiri dari jumlah dompol bunga per cabang, jumlah dompol putik per cabang, jumlah dompol buah hijau per cabang, jumlah dompol buah merah per cabang, jumlah buah per dompol, jumlah biji panen per cabang, bobot buah segar per cabang, bobot biji kering per cabang, dan produksi per pohon. Pengamatan variabel produksi dilakukan setiap satu bulan sekali kecuali parameter jumlah dompol buah merah percabang, jumlah biji panen per cabang, bobot buah segar per cabang, dan bobot biji kering per cabang dilakukan pada saat panen pertama. Produksi per pohon dihitung menggunakan rumus sebagai berikut:

Produksi per pohon $=$ Jumlah cabang primer per pohon $\mathrm{x}$ Jumlah dompol buah hijau per cabang x Bobot biji per dompol

Data yang diperoleh diuji Homogenitas ragam diuji dengan uji Barlett dan kemenambahan data dengan uji Tukey, bila memenuhi asumsi maka data dianalisis ragam dan dilanjutkan dengan Uji Beda Nyata Terkecil (BNT) pada taraf 5\%.

\section{HASIL DAN PEMBAHASAN}

Hasil penelitian menunjukkan bahwa berbagai sistem penyambungan kopi Arabika dan Robusta tidak berpengaruh nyata terhadap parameter pertumbuhan yaitu diameter cabang primer, panjang cabang primer, dan panjang cabang ujung produktif. Sistem penyambungan berpengaruh nyata pada jumlah cabang primer (PII), dan jumlah cabang plagiotrop B0, B1 dan B2 $(\mathrm{p}<0,05)($ Tabel 1).

Tabel 2 menunjukkan bahwa sistem penyambungan tidak berpengaruh terhadap jumlah 
cabang primer yang diamati pada PI (bulan Oktober 2019), diameter cabang primer, panjang cabang primer, dan panjang cabang ujung. Kemarau panjang pada bulan Oktober sampai Desember 2019 (BMKG, 2019) menyebabkan pertumbuhan cabang primer sangat lambat. Sistem penyambungan berpengaruh nyata pada jumlah cabang primer pada pengamatan April 2020 dimana kopi sambungan Robusta/Robusta menghasilkan jumlah cabang primer yang terbanyak. DaMatta et al. (2017) melaporkan pertumbuhan cabang kopi berlangsung cepat ketika musim hujan. Evizal et al. (2018) melaporkan pertumbuhan cabang kopi grafting Robusta/Robusta lebih cepat dari pada kopi grafting Arabika/Robusta.

Sistem penyambungan berpengaruh nyata terhadap jumlah cabang plagiotrop B0, B1 dan B2 dimana kopi sambungan Robusta/Robusta cenderung menghasilkan cabang plagiotrop yang lebih banyak (Tabel 3). Sistem penyambungan Robusta/Robusta umum dilakukan petani untuk meningkatkan pertumbuhan cabang plagiotrop yang lebih baik daripada kopi Robusta non-grafting (Evizal dan Prasmatiwi, 2020). Pertumbuhan kopi grafting Robusta/ Robusta (Pranowo dan Supriadi, 2013) maupun Arabika/Robusta (Tomaz et al., 2002) dipengaruhi oleh klon batang atas dan bawah yang digunakan.

Tabel 1. Rekapitulasi hasil analisis ragam pengaruh sistem penyambungan batang kopi Arabika dengan Robusta terhadap parameter pertumbuhan

\begin{tabular}{clc}
\hline No & \multicolumn{1}{c}{ Peubah } & Signifikasi \\
\hline 1 & Jumlah Cabang Primer (PI) & tn \\
2 & Jumlah Cabang Primer (PII) & $*$ \\
3 & Diameter Cabang Primer (cm) & tn \\
4 & Panjang Cabang Primer (cm) & tn \\
5 & Panjang Cabang Ujung Produktif $(\mathrm{cm})$ & tn \\
6 & Jumlah Cabang Plagiotrop (B0) & $*$ \\
7 & Jumlah Cabang Plagiotrop (B1) & $*$ \\
8 & Jumlah Cabang Plagiotrop (B2) & $*$ \\
\hline
\end{tabular}

Keterangan: PI (Pengamatan jumlah cabang primer bulan Oktober 2019); PII (Pengamatan jumlah cabang primer bulan April 2020); tn $=$ Tidak Berbeda pada taraf 5\%; * = Berbeda pada taraf 5\%

Tabel 2. Pengaruh sistem penyambungan terhadap pertumbuhan cabang primer

\begin{tabular}{lccccc}
\hline \multirow{2}{*}{ Sistem Penyambungan } & $\begin{array}{c}\text { Jumlah cabang } \\
\text { primer (PI) }\end{array}$ & \multicolumn{2}{c}{$\begin{array}{c}\text { Jumlah cabang } \\
\text { primer (PII) }\end{array}$} & $\begin{array}{c}\text { Diameter cabang } \\
\text { primer (cm) }\end{array}$ & $\begin{array}{c}\text { Panjang cabang } \\
\text { primer (cm) }\end{array}$ \\
\cline { 2 - 6 } & Asli & Asli & Log (x) & Asli & Asli \\
\hline Arabika non-grafting & 18,5 & 28,00 & $1,43 \mathrm{ab}$ & 0,94 & 49,63 \\
Arabika Plagiotrop/Robusta & 9,25 & 23,38 & $1,36 \mathrm{~b}$ & 0,85 & 55,49 \\
Arabika Orthrotrop/Robusta & 17,25 & 26,75 & $1,42 \mathrm{ab}$ & 0,68 & 53,06 \\
Arabika/Robusta + cabang & 12,44 & 21,31 & $1,32 \mathrm{~b}$ & 0,65 & 51,06 \\
Robusta non-grafting & 14,75 & 16,00 & $1,20 \mathrm{c}$ & 0,90 & 67,81 \\
Robusta/Robusta & 16,75 & 33,5 & $1,52 \mathrm{a}$ & 0,74 & 63,50 \\
\hline BNT 5\% & \multicolumn{5}{c}{0,12} \\
\hline
\end{tabular}

Keterangan: Nilai tengah pada setiap kolom yang diikuti huruf yang sama tidak berbeda nyata pada uji BNT pada taraf 5\%, PI (Pengamatan jumlah cabang primer Oktober 2019), PII (Pengamatan jumlah cabang primer April 2020). 
Tabel 3. Pengaruh sistem penyambungan terhadap cabang plagiotrop

\begin{tabular}{lcccccc}
\hline Sistem Penyambungan & $\begin{array}{c}\text { Panjang cabang } \\
\text { plagiotrop ujung } \\
(\mathrm{cm})\end{array}$ & $\begin{array}{c}\text { Jumlah cabang } \\
\text { plagiotrop B0 }\end{array}$ & \multicolumn{2}{c}{$\begin{array}{c}\text { Jumlah cabang } \\
\text { plagiotrop B1 }\end{array}$} & \multicolumn{2}{c}{$\begin{array}{c}\text { Jumlah cabang } \\
\text { plagiotrop B2 }\end{array}$} \\
\cline { 2 - 7 } & Asli & Asli & Asli & Log (x) & Asli & Arcsin \\
\hline Arabika non-grafting & 15,69 & $7,75 \mathrm{ab}$ & 16,00 & $1,16 \mathrm{~b}$ & 5,63 & $11,78 \mathrm{ab}$ \\
Arabika Plagiotrop/Robusta & 17,31 & $1,00 \mathrm{c}$ & 16,13 & $1,17 \mathrm{~b}$ & 0,25 & $2,03 \mathrm{c}$ \\
Arabika Orthrotrop/Robusta & 14,50 & $5,63 \mathrm{ab}$ & 20,75 & $1,30 \mathrm{ab}$ & 4,38 & $11,95 \mathrm{ab}$ \\
Arabika/Robusta + cabang & 17,00 & $4,38 \mathrm{~b}$ & 13,50 & $1,12 \mathrm{~b}$ & 4,00 & $11,45 \mathrm{ab}$ \\
Robusta non-grafting & 19,63 & $6,75 \mathrm{ab}$ & 16,25 & $0,76 \mathrm{c}$ & 3,38 & $10,16 \mathrm{~b}$ \\
Robusta/Robusta & 17,56 & $9,88 \mathrm{a}$ & 26,50 & $1,38 \mathrm{a}$ & 6,50 & $14,17 \mathrm{a}$ \\
\hline BNT 5\% & & 4,29 & & 0,20 & & 5,95 \\
\hline
\end{tabular}

Keterangan : Nilai tengah pada setiap kolom yang diikuti huruf yang sama tidak berbeda nyata pada uji BNT pada taraf $5 \%$.

Tabel 4. Rekapitulasi hasil analisis ragam pengaruh sistem penyambungan batang kopi Arabika dengan Robusta terhadap parameter produksi

\begin{tabular}{clc}
\hline No & \multicolumn{1}{c}{ Peubah } & Signifikasi \\
\hline 1 & Jumlah Dompol Bunga per Cabang & $*$ \\
2 & Jumlah Dompol Putik per Cabang & $*$ \\
3 & Jumlah Dompol Buah Hijau per Cabang & $*$ \\
4 & Jumlah Buah per Dompol per Cabang & tn \\
5 & Bobot Buah Segar per Cabang (g) & $*$ \\
6 & Bobot Biji Kering per Cabang & $*$ \\
7 & Jumlah Biji Panen per Cabang & $*$ \\
8 & Produksi per Pohon $(\mathrm{kg})$ & $*$ \\
\hline
\end{tabular}

Keterangan: $\mathrm{tn}=$ Tidak Berbeda pada taraf $5 \%, *=$ Berbeda pada taraf $5 \%$

Hasil analisis ragam menunjukkan berbagai sistem penyambungan mempengaruhi jumlah dompol bunga per cabang, jumlah dompol putik per cabang, jumlah dompol buah hijau per cabang, bobot buah segar per cabang, Bobot biji kering per cabang, jumlah biji panen per cabang, dan produksi per pohon (Tabel 4). Jumlah dompol bunga per cabang terbanyak dihasilkan oleh kopi Robusta non-grafting. Jumlah dompol putik per cabang terbanyak dihasilkan oleh kopi Arabika Plagiotrop/Robusta namun tidak berbeda nyata dengan Robusta non-grafting dan Robusta grafting. Jumlah dompol buah hijau per cabang terbanyak diperoleh pada kopi Arabika Plagiotrop/Robusta namun tidak berbeda nyata dengan kopi Arabika Orthrotrop/Robusta(Tabel 5).
Tabel 6 menunjukkan pengaruh sistem penyambungan terhadap komponen hasil kopi Arabika. Kopi grafting Arabika Plagiotrop/Robusta menghasilkan bobot buah segar per cabang dan bobot biji kering per cabang yang tertinggi. Kopi grafting Arabika Plagiotrop/Robusta memberikan produksi buah per pohon yang lebih tinggi daripada kopi Arabika nongrafting, namun tidak berbeda nyata dengan sistem grafting Arabika Ortotrop/Robusta. Alnopri dan Hermawan (2015) telah melaporkan bahwa pertumbuhan kopi graftingArabika/Robusta lebih baik daripada kopi Arabika non-grafting, baik pada kopi Arabika USDA-230762, S-1934, Kartika, maupun Andungsari. Tomaz et al. (2005) juga melaporkan 
Tabel 5. Pengaruh sistem penyambungan terhadap komponen dompolan

\begin{tabular}{lcccccc}
\hline \multirow{2}{*}{ Sistem Penyambungan } & $\begin{array}{c}\text { Jumlah dompol } \\
\text { bunga/cab }\end{array}$ & $\begin{array}{c}\text { Jumlah dompol } \\
\text { putik/cab }\end{array}$ & \multicolumn{2}{c}{$\begin{array}{c}\text { Jumlah dompol } \\
\text { buah hijau/cab }\end{array}$} & $\begin{array}{c}\text { Jumlah buah } \\
\text { per dompol }\end{array}$ \\
\cline { 2 - 7 } & Asli & Asli & $\sqrt{ } \sqrt{ }(\mathrm{x}+0,5)$ & Asli & $\sqrt{ } \sqrt{ }(\mathrm{x}+0,5)$ & Asli \\
\hline Arabika non-grafting & $6,56 \mathrm{c}$ & 2,75 & $1,62 \mathrm{bc}$ & 7,00 & $2,69 \mathrm{~b}$ & 13,25 \\
Arabika Plagiotrop/Robusta & $9,69 \mathrm{~b}$ & 6,06 & $2,53 \mathrm{a}$ & 11,81 & $3,50 \mathrm{a}$ & 18,50 \\
Arabika Orthrotrop/Robusta & $5,88 \mathrm{~d}$ & 1,25 & $1,25 \mathrm{c}$ & 9,00 & $3,07 \mathrm{ab}$ & 15,75 \\
Arabika/Robusta + cabang & $5,50 \mathrm{~d}$ & 3,06 & $1,88 \mathrm{~b}$ & 7,47 & $2,8 \mathrm{~b}$ & 18,25 \\
Robusta non-grafting & $11,94 \mathrm{a}$ & 4,25 & $2,17 \mathrm{ab}$ & 5,63 & $2,44 \mathrm{bc}$ & 14,06 \\
Robusta/Robusta & $6,00 \mathrm{c}$ & 5,19 & $2,35 \mathrm{ab}$ & 5,75 & $2,50 \mathrm{bc}$ & 16,00 \\
\hline BNT 5\% & 1,53 & & 0,65 & & 0,43 & \\
\hline
\end{tabular}

Keterangan : Nilai tengah pada setiap kolom yang diikuti huruf yang sama tidak berbeda nyata pada uji BNT pada taraf $5 \%$.

Tabel 6. Pengaruh sistem penyambungan terhadap komponen hasil kopi Arabika

\begin{tabular}{|c|c|c|c|c|c|c|c|c|}
\hline \multirow[t]{2}{*}{ Sistem Penyambungan } & \multicolumn{2}{|c|}{$\begin{array}{c}\text { Bobot buah } \\
\text { segar/cabang }(g)\end{array}$} & \multicolumn{2}{|c|}{$\begin{array}{l}\text { Bobot biji } \\
\text { kering/ } \\
\text { cabang (g) }\end{array}$} & \multicolumn{2}{|c|}{$\begin{array}{l}\text { Jumlah biji panen } \\
\text { per cabang }\end{array}$} & \multicolumn{2}{|c|}{$\begin{array}{l}\text { Produksi per } \\
\text { pohon }(\mathrm{kg})\end{array}$} \\
\hline & Asli & $\log (\mathrm{x})$ & Asli & $\log (\mathrm{x})$ & Asli & $\log (\mathrm{x})$ & Asli & $\sqrt{\sqrt{ }(x+0,5)}$ \\
\hline Arabika non-grafting & 12,29 & $0,96 \mathrm{~b}$ & 2,41 & $1,24 \mathrm{~b}$ & 15,63 & $1,05 \mathrm{~b}$ & 0.96 & $1,17 \mathrm{~b}$ \\
\hline Arabika Plagiotrop/Robusta & 45,44 & $1,60 \mathrm{a}$ & 8,04 & $1,84 \mathrm{a}$ & 49,81 & $1,63 \mathrm{a}$ & 1.66 & $1,46 \mathrm{a}$ \\
\hline Arabika Orthrotrop/Robusta & 14,73 & $0,93 \mathrm{~b}$ & 3,16 & $1,25 \mathrm{~b}$ & 18,56 & $1,08 \mathrm{~b}$ & 1.16 & $1,27 \mathrm{ab}$ \\
\hline Arabika/Robusta + cabang & 12,98 & $1,04 \mathrm{ab}$ & 2,69 & $1,34 \mathrm{ab}$ & 16,56 & $1,15 \mathrm{~b}$ & 0.89 & $1,17 \mathrm{~b}$ \\
\hline Robusta non-grafting & 0 & $0,00 \mathrm{c}$ & 0 & $0,00 \mathrm{c}$ & 0 & $0,00 \mathrm{c}$ & 0.00 & $0,71 \mathrm{c}$ \\
\hline Robusta/Robusta & 0.00 & $0,00 \mathrm{c}$ & 0 & $0,00 \mathrm{c}$ & 0 & $0,00 \mathrm{c}$ & 0.00 & $0,71 \mathrm{c}$ \\
\hline BNT 5\% & & 0,4 & & 0,41 & & 0,38 & & 0.24 \\
\hline
\end{tabular}

Keterangan : Nilai tengah pada setiap kolom yang diikuti huruf yang sama tidak berbeda nyata pada uji BNT pada taraf 5\%.

bahwa kopi grafting Arabika/Robusta dapat meningkatkan pertumbuhan dan hasil kopi Arabika.

Peningkatan produktivitas kebun kopi sambungan telah dilaporkan oleh Evizal dan Prasmatiwi (2020) baik menggunakan batang bawah kopi lokal intraspesifik Robusta/Robusta maupun maupun interspesifik Robusta/Liberika. Peningkatan produksi kopi grafting interspesifik Arabika/Liberika telah dilaporkan oleh Myers et al. (2020).

Junior et al. (2013) menyatakan bahwa hasil penyambungan merupakan metode yang dapat mempertahankan sifat genetik dari indukan sumber entres. Untuk mendapatkan kompatibilitas serta produksi yang tinggi harus dipilih batang atas yang unggul. Nurhaida et al. (2005) melaporkan bahwa penyambungan kopi Robusta/Robusta di kebun merupakan praktek tradisional petani kopi di Lampung Barat sebagai upaya pemeliharaan untuk meningkatkan produktivitas kopi Robusta. Cramer (1957) melaporkan bahwa penyambungan kopi Arabika/Robusta dilaksanakan dengan tujuan mengkonversi pertanaman kopi Robusta menjadi pertanaman kopi Arabika. Penyambungan kopi Robusta/Robusta dilakukan untuk peremajaan kebun kopi tua atau untuk perbaikan klonal pohon-pohon yang kurang produktif. 


\section{KESIMPULAN}

Pertumbuhan dan produksi pada tanaman kopi grafting dapat lebih tinggi daripada tanaman non grafting. Pada kopi Robusta grafting ditunjukkan oleh variabel jumlah cabang primer, jumlah cabang B1 dan B2. Pada kopi Arabika grafting ditunjukkan oleh variabel jumlah dompol bunga,jumlah dompol putik per cabang, jumlah dompol buah per cabang, bobot segar buah per cabang, jumlah biji panen pertama dan produksi per pohon. Dari berbagai sistem penyambungan kopi Arabika grafting interspesifik, sistem penyambungan Arabika Plagiotrop/Robusta memberikan komponen produksi lebih tinggi yaitu pada variabel jumlah dompol bunga per cabang, jumlah dompol putik per cabang, dan jumlah biji panen per cabang. Sistem penyambungan Arabika Plagiotrop/Robusta memberikan produksi per pohon tertinggi namun tidak berbeda nyata dengan sistem penyambungan Arabika Ortotrop/Robusta.

\section{DAFTAR PUSTAKA}

Alnopri and B. Hermawan. 2015. Sustainability for growth and productivity of Arabica coffee in lowland regions of Bengkulu Province. International Journal on Advanced Science Engineering Information Technology. 5(5): 304- 307.

Badan Meteorologi Klimatologi dan Geofisika (BMKG). 2019. Data iklim bulan Oktober hingga Desember 2019. Stasiun Klimatologi Pesawaran. Lampung.

Bertrand, B. and H. Etienne. 2001. Growth, production, and bean quality of Coffea Arabica as affected by interspesific grafting: Consequences for rootstock breeding. Hort Science. 36(2): 269-273.
Coolhaas, C. 1953. The use of branch grafting for Robusta coffee in Java. Netherlands Journal of Agricultural Science. 1(2): 130-136.

Cramer, P.J.S. 1957. A Review Literature of Coffee Research in Indonesia from about 1602-1945. Inter-American Institute of Agriculture Science. Turrialba, Costa Rica.

DaMatta, F.M., C.P. Ronchi, M. Maestri, and R.S. Barros. 2007. Ecophysiology of coffee growth and production. Brazilian Journal of Plant Physiology. 19(4):485-510.

Direktorat Jenderal Perkebunan, 2019. Statistik Perkebunan Indonesia Komoditas Kopi 2018-2020. Sekretariat Direktorat Jenderal Perkebunan. Jakarta.

Evizal, R. 2013. Etno-agronomi pengelolaan perkebunan kopi di Sumberjaya Kabupaten Lampung Barat. Agrotrop. 3(2): 1-13.

Evizal, R., Sugiatno, S.D. Utomo, H. Pujisiswanto, S. Widagdo, F.E. Prasmatiwi, dan A.D. Stiawan. 2018. Growth performance of mature trees resulted from intra and inter-spesific grafting on Robusta coffee. Planta Tropika. 6(2): 77-83.

Evizal, R. dan Prasmatiwi, F. E., 2019. Pertanian Spesifik Lokasi: Etnoagronomi ragam kopi grafting di Lampung. Makalah pada Seminar Nasional Teknologi Pertanian(TEKTAN VIII) Politeknik Negeri Lampung.

Evizal, R. dan F.E. Prasmatiwi. 2020. Agroteknologi kopi grafting untuk peningkatan produksi. Jurnal Agrotek Tropika. 8(2): 423-434.

Evizal, R., F.E. Prasmatiwi, S. Widagdo, dan H. Novpriansyah. 2020. Etno-Agronomi budidaya kopi yang toleran variabilitas curah hujan. Jurnal Agro Industri Perkebunan. 8(1): 49-59. 
Junior, A. De S., S.R.Alexander, R.E. Scmhmildt, L.F. Partelli, G.A.M. Ferrao, and L. Mauri, L. 2013. Comparison between grafting and cutting as vegetative propagation methods for conilon coffee plants. Journal Acta Scientiarum. 35(4): 461-469.

Myers, R., A. Kawabata, A. Cho, and S.T. Nakamoto. 2020. Grafted coffee increases yield and survivability. HortTechnology. 30(3): 428-432.

Novaes, P., J.P. Souza, and C.H.B.A. Prado. 2011. Grafting for improving net photosynthesis of coffea arabica in field in Southeast of Brazil. Expl. Agric. 47(1): 53-58.

Nurhaida, I., S.P. Hariyanto, S. Bakri, A. Junaidi, dan P. Syah. 2005. Penginventarisan kearifan lokal dalam praktik wanatani kopi dalam debat kelestarian fungsi hidro-orologis wilayah resapan di Lampung Barat. Jurnal Pembangunan Pedesaan. 5(2): 91-105.

Pham, T.T., B.L. Giang, N.H. Nguyen, P.N.D. Yen, V.D.M. Hoang, B.T.L. Ha and N.T.T. Le. 2020. Combination of Mycorrhizal Symbiosis and Root Grafting Effectively Controls Nematode in Replanted Coffee Soil. Plant. 9(555):1-11. doi:10.3390/plants9050555.
Pranowo, D. and Supriadi, H. 2013. Evaluation of Grafted Plants from Nine of Robusta Coffee Clones with Local Rootstock. Journal Buletin Ristri.4(3): 231-236.

Pusat Data dan Informasi Pertanian. 2016. Outlook Kopi, Komoditas Pertanian Subsektor Perkebunan. Sekretariat Jenderal Kementrian Pertanian. $93 \mathrm{hlm}$.

Rahardjo, P. 2012. Panduan Budidaya dan Pengolahan Kopi Arabika dan Robusta. Penebar Swadaya. Jakarta.

Tomaz, M.A., N.S. Sakiyama, H.E.P. Martinez, A.A. Pereira, L. Zambolim, and C.D. Cruz. 2002. Grafted young coffee tree growth in a greenhouse. Crop Breeding and Applied Biotechnology. 2(3): 425-430.

Tomaz, M.A., N.S. Sakiyama, H.E.P. Martinez, C.D. Cruz, A.A. Pereira, R.S. de Freitas. 2005. Rootstocks affecting the development of Coffea arabica L. young plants. Ciencia Rural. 35(3): 570-575. 